\title{
The Processes of Modernization in the Russian Regions of the Circumpolar Zone: Possibilities and Limitations
}

\author{
Romashkina G. ${ }^{a}$ \\ Didenko N.b \\ a Tyumen State University, Tyumen, Russia \\ ${ }^{b}$ Peter the Great St. Petersburg Polytechnic University, Russia \\ Email: didenko.nikolay@mail.ru (Didenko Nikolay)
}

Doi:10.5901/mjss.2015.v6n6s4p264

\begin{abstract}
The authors of the present work studied the socio-economic and technological development of the regions of the Arctic zone of the Russian Federation. The object of analysis is the process of modernization, acting as a mechanism for the transition from traditional to modern society. Theoretical and methodological basis for the consideration of the modernization process is the concept and methodology of Chinese researcher He Chuanqi (China Center for Modernization Research of the Chinese Academy of Sciences). Modernization is considered in its historical perspective. It is presented as a series of primary and secondary upgrading or modernizing integrated as an alternative for the countries and regions of the catching-up development. The authors demonstrated the strengths and weaknesses of the socio-economic development of regions of the Russian Arctic zone. It is shown that the processes of modernization lags behind the national average rates in the Arctic regions. Their characteristic is the superiority of the social component on the other, as in Russia on average. The authors studied the basic contradiction of the moment. Its essence lies in the fact that the regions of Russia, most successfully developing in socioeconomic and socio-cultural spaces at the same time are not those in the space of modernization changes. The authors carried out a detailed comparative analysis of the processes of modernization in the Murmansk region, the Yamalo-Nenets Autonomous District, the Nenets Autonomous District, the Arkhangelsk region in the Russian and global contexts. The state program of development of the Russian Arctic, currently being implemented, had an impact on the dynamics of development, but the qualitative transition to a different development path has not happened yet. The paper shows a deadlock on energy resources and development options. The slow pace of modernization contribute to widening the gap with developed countries. Regions remain in the paradigm of resource economics. It does not allow them to implement the transition to a new, innovative type of development.
\end{abstract}

Keywords: Arctic, region, index, industrial, post-industrial, development, process, knowledge economy, economic, modernization, comparative studies.

\section{Introduction}

Accelerated development of the Russian Arctic is a question of strategic importance for Russia. In the existing circumstances Russia should not give the other countries any chance to open up the discussion on the internationalization of the Northern Sea Route and several Arctic natural resources that are within the Russian Arctic zone. The Arctic territory is claimed not only by traditional Arctic countries, but also those who are interested in the development the Arctic shelf as well as of the international transport and trade. That makes the question of creating and re-creating of the prerequisites for forming of strong and dynamically developing Arctic zone extremely vital.

For that purpose the Arctic zone should be connected with the modernization processes. Different countries and regions follow the way of modernization with varying pace. The world modernization is viewed as long historical process that can be subdivided into two main periods: the primary and secondary modernization. The primary modernization (PM) - is the transition from the agricultural civilization to an industrial one. It can also be called the transition from agricultural to industrial economics. The secondary modernization (SM) - is the transition from the industrial civilization to a knowledge-based one. As He Chuanqi points out, the primary civilization shows itself through capital, technology and democracy, while the secondary modernization can become visible through innovations of knowledge, institutes and human capital.

We are interested in the ranking of the Russian Arctic zone in the world modernization process. It should be determined because dominating some territory includes also the modernization aspect. The more the territory is 
modernized the more inner resources for development it possesses. To the contrary, the regional stagnation and recession leads to the absence on any further development perspective. It concerns not only Russia but its Arctic territories as well.

In order to carry out the analysis of modernization processes in Russia and in its regions, the article gives the characteristic of the main components of the modernization process. It is shown afterwards, that the components are spontaneous on the federal level and quite fragmented of the regional one. Finally the article presents the modernization level of the Russian arctic regions.

\section{The General Characteristic of the Analysis Methodology}

As the classical modernization theory says, the development of the human civilization includes three main periods: the primitive society, the traditional agrarian society and the modern industrial society. The modernization process is the process of transformation of the society from the traditional agrarian type to the modern industrial one. Even the countries that are unable to accept modernization and prefer to maintain the traditional lifestyle are influenced by social changes, whereas the lag in welfare and quality of life between these countries and the leaders widens. In the 1960-s all the industrially developed countries have finished the classical modernization and a new trend could be found in their development. The development focus have shifted away from urbanization to disurbanization. The trend of shifting from industrialization to deindustrialization emerged. The latter expressed in constantly declining share of industrial production and growing share of services in the economy. The so called post-industrial society has excepted only several elements of the industrial society, adding instead some new ones. During the modernization process all the countries were trying to define the economic development and the degree it corresponds with the modern trends. That enabled to introduce the national concept of the transition to the post-industrial society. The necessity of revision of the classical modernization theory has emerged. If the classical modernization theory describes the industrial world, then the post-modern theory researches its further development.

As it is stated in the overview report on modernization in the world and in China, in 1980-s and in 1990-s research of modernization has given birth to many new theories. Among them one can mention the theory of ecological modernization of J.Huber (1985), the theory of reflexive modernization of U.Beck (1986), the theory of continuing modernization of W.Zapf (1991), "the new modernization" of E.Tiriakyan (1991) and some other concepts including the theory of secondary modernization of He Chuanqi (1998), which served as the basis for the analysis.

Modernization of economics is traditionally related with need for innovative development. The assessment systems of innovative development of a country have been worked out. The countries are rated with the indicators of innovative and technological development.

The concept of He Chuanqi can be distinguished among all the previous ones. The international modernization is viewed as a long historical process that can be divided into two major periods: the initial and the secondary modernization. The initial modernization (IM) is the period of transition from the agrarian civilization to the industrial one. The IM means also the transition to the industrial era, economics, society, culture, etc. The secondary modernization is the transition from the industrial civilization to the civilization of knowledge. The transition to the informational economics, society and culture can be observed at the same time. The transition from the so called material culture to the postmaterial culture takes place. As He Chuanqi notices the dynamics of the IM can be traced through capital, technology and democracy, whereas the dynamics if the SM can be viewed through innovation in knowledge, institutes and human capital. Both types of modernization can be modeled in several ways and depend on the ways of realization.

The assessment model for the primary modernization has been worked out with consideration of the assessment indicators introduced by the American researcher A. Inkeles in the 1980-s. Bearing in mind that modernization in general means improvement, changing in accordance with modern requirements, one should work out the criteria of modernity, i.e. one needs a specimen. For instance, the most developed countries can be taken as a standard for social beautification.

It's important to notice that in various countries and regions the civilization process wasn't a synchronized one, so, that various combinations of the development stages are possible. The developed countries (the leading countries) are going gradually through these stages: first the primary modernization finishes, then the transition to the secondary modernization takes place. The developing countries (the catching-up economies) under the international competition are trying to overtake each other and reach a higher development level while combining the realization of both primary (industrial) and secondary (informational) modernization. The coordinated development of the both modernization stages is called integrated modernization (IM). Here it is important to point out, that the integrated modernization is the third type of modernization development. 
In order to make an unbiased appraisal of modernization in different countries and regions the methodology for assessment of the modernization potential of a country has been worked out within the Modernization Study Center (MSC) of the Chinese Academy of Sciences. The MSC published 11 reports on the "Modernization in the world and in China" during the period 2001-2012. The reports were based on the statistical data of 131 countries (97\% of the world population) including Russia, and for the moment we obtain the data up to the year 2012.

In order to analyze modernization of Russia and its regions the methodology was adapted under the leadership of N.Lapin The modernization level in various Russian regions was estimated.

The toolset for estimating regional modernization consists of three types of indices: a primary modernization index (PMI), a secondary modernization index (SMI) and an integrated modernization index (IMI). Each of the indices includes sub indices reflecting the level of modernization in the economic, social and informational sectors. The PMI is capable of describing the modernization process in the developing countries (and regions), the SMI-index can be better applied to characterize modernization in the developed countries (and regions), while the IMI-index shows the relative levels of modernization for the both. For each of the modernization stages the estimation model was created. Each model consists of its own set of indicators and their standard values. For estimation of the primary modernization 10 indicators for three main spheres of the industrial society are used. These spheres are economics, social sphere and the level of knowledge (see Table 1).

Table 1: The indicators of modernization

\begin{tabular}{|c|}
\hline The primary modernization (PMI) \\
\hline $\begin{array}{l}\text { The economic indicators: GRP per capita in USD; the share of the population employed in agriculture out of total employed, } \\
\text { in \%; the share of the added value in agriculture in the GRP, in \%; the share of the added value in the sphere of services in the } \\
\text { GRP, in \%. }\end{array}$ \\
\hline $\begin{array}{l}\text { The social indicators: the share of urban population, in \%; the number of doctors per } 1000 \text { pers., in ppm; the infant mortality } \\
\text { rate, in ppm; the life expectancy in years. }\end{array}$ \\
\hline $\begin{array}{l}\text { The level of knowledge indicators: the rate of literacy between adults, in \%; the share of university students out of the } \\
\text { population aged } 18-22 \text { years old, in \%. }\end{array}$ \\
\hline The secondary modernization (SMI) \\
\hline $\begin{array}{l}\text { Knowledge innovation: the share of R\&D expenditures in the GRP, in \%; the number of researchers and engineers employed } \\
\text { in R\&D per } 10000 \text { pers.; the number of residents applied for a patent per } 1 \mathrm{mln} \text {. of population. }\end{array}$ \\
\hline $\begin{array}{l}\text { Translation of knowledge: the share of secondary school students out of the population aged 12-17 years old, in \%; the share } \\
\text { of university students out of the population aged 18-22 years old, in \%; the number of TV-sets per } 100 \text { households; the number } \\
\text { of PC per } 100 \text { households. }\end{array}$ \\
\hline $\begin{array}{l}\text { Quality of life: the share of urban population, in \%; the number of doctors per } 1000 \text { pers., in ppm; the infant mortality rate, in } \\
\text { ppm; the life expectancy in years; per capita energy consumption: the per capita crude oil equivalent in kg. }\end{array}$ \\
\hline $\begin{array}{l}\text { Quality of economics: the GRP per capita in USD; the per capita GRP at purchasing power parity in USD; the share of the } \\
\text { added value in production in the GRP, in \%; the share of the population employed in production out of total employed, in \%. }\end{array}$ \\
\hline The integrated modernization (IMI) \\
\hline $\begin{array}{l}\text { The economic indicators: the per capita GRP in USD; the per capita GRP at purchasing power parity in USD; the share of } \\
\text { the added value in services in the GRP, in \%; the share of the population employed in services out of total employed, in \%. }\end{array}$ \\
\hline $\begin{array}{l}\text { The social indicators: the share of urban population, in \%; the number of doctors per } 1000 \text { pers., in ppm; the life expectancy } \\
\text { in years; the ecological effectiveness: the per capita GRP divided by per capita energy consumption. }\end{array}$ \\
\hline $\begin{array}{l}\text { The knowledge indicators: the share of R\&D expenditures in the GRP, in \%; the number of residents applied for a patent per } \\
1 \mathrm{mln} \text {. of population; the share of university students out of the population aged } 18-22 \text { years old, in \%; the number of Internet }\end{array}$ \\
\hline
\end{tabular}

In the proposed by the MSC of the Chinese Academy of Sciences methodology for estimation of the primary modernization some average indicator values achieved by 19 most industrially developed countries in 1960 were taken as standard ones. Afterwards with the help of proportional relations method the correspondence degree of the separate indicator with its standard value is calculated. The maximal possible value is $100 \%$ (if the indicator value outperforms the standard value it is set to $100 \%$ either). If the $100 \%$ correspondence level is achieved, then one supposes that the indicator has reached the PMI level. Finally the PMI is determined with the arithmetic average of all the indicators.

Because each of the stages includes 4 evolutionary phases (inception, growth, boom and transition to the next stage), comparing real and standard values of the four signal indicators one can aggregately determine the phase of the primary and the secondary modernization.

As it was already mentioned the secondary modernization is connected with the information era or the knowledge 
era. That means that exactly the knowledge innovation, the knowledge usage and transfer constitute its main driving force. The estimation of the secondary modernization includes 4 groups of indicators (see the second part of Table 1).

The index of separate indicators is calculated with the proportional relations method. The maximum value of the index is set to 120 (if the value exceeds 120 , it is still taken as 120). The indices of knowledge innovation, knowledge transfer, quality of life and quality of economics are calculated as arithmetic averages of the corresponding sub indices. Further the index of the secondary modernization is calculated as an arithmetic average of the four indicators.

The list of indicators can be changed over time. It is explained with the fact that however the secondary modernization was launched over 30 years ago in the developed countries, its laws and inherent features are still forming. As the author of the methodology points out, together with the evolvement of the secondary modernization the methods and indicators used for its estimation should be adjusted either. Currently the standard indicator values for SMI estimation are set on the average performance level of the developed countries during the last year.

It should be mentioned, that the author of the methodology, professor He distinguishes the third modernization way - the integrated one, which is optimal for the catch-up development countries. For estimation of this modernization way a set of IMI indices exist. As for the PMI the standard value for the IMI is based on the average values of the developed countries for the corresponding year. The IMI value is determined as the arithmetic average of all the indicators. The method of calculation can be seen in Table 2 .

\section{The Modernization Stage Dynamics in Russia and Its Arctic Regions}

According with monitoring results of the Modernization Study Center (Chinese Academy of Sciences) 35 countries out of 135 have accomplished the primary modernization stage by $100 \%$ or more by 2006 . That means that this countries have reached or exceeded the level of 18 industrially developed countries reached by the beginning of 1960-s. By 2006 Russia has accomplished this modernization stage by $97 \%$, ranked 41.8 out of 10 indicators were valued $100 \%$ (totally matched the standard values), while only 2 indices were below 100\% - the per capita GDP index (78\% of the standard value) and life expectancy index ( $94 \%$ of the standard value, 70 years). Because of rapid rise of the oil and gas receipts the per capita GDP index exceeded the standard value by 2008 , while the life expectance index grown up to $97 \%$. In general the Russian PMI has grown up to $99.7 \%$, and the rank of the country became 1 step higher (rank 40). The world economic crisis of 2008 has negatively affected the growth in many countries including Russia.

Up to 2010 the Russian PMI grew from 97 to 99.8 points, which is slightly lower $100 \%$ due to low life expectancy index (98\%). Because the international competition however Russian rank moved downwards to the 43-th position. The economies of such countries as Kuwait, Brazil and Turkey grew faster. For the period the average PMI of 131 countries was 96 points with a giant gap within the countries: the PMI varied from 32 to 100 points.

During the period the regions of the Russian circumpolar zone ${ }^{1}$ are substantially lagging behind even the average Russian indicators in terms of primary modernization (see. Figure 1). The Murmansk region is pretty close to average Russian trend, while the Arkhangelsk region, the Sakha Republic and the Krasnoyarsk region are slightly behind it. The fast development of modernization of the first five years of 2000s was changed by unsteady growth periods and in some regions even the declining economic activity was observed.

The substantial gap is demonstrated by the Nenetsk region, where the PMI of $92.2 \%$ in 2000 declined to $90.7 \%$ in 2012. Unsteady development of the Chukchee Autonomous district, the Krasnoyarsk region and the Sakha republic can be explained by the strong influence of the crisis of 2008-2009. The Chukchee Autonomous district even up to 2012 could not reach the level of 2005. But the regions are not outsiders in respect to the GRP indictors. But the main reason of uncompleted primary modernization stage in the northern regions is underdeveloped sector of services and anachronistic employment structure. But generally all the regions are over $90 \%$ of the development level performed by the 18 developed countries at the beginning of 1960-s.

\footnotetext{
1 The Murmansk region, the Nenetsk, Chukchee and Yamal-Nenetsk Autonomous districts, as well as city of Norilsk, the territories of Taymyr and Turukhan regions of the Krasnoyarsk district, some territories of the Arkhangelsk region and some northern regions of Yakutia, territories an islands in the Arctic Ocean.
} 


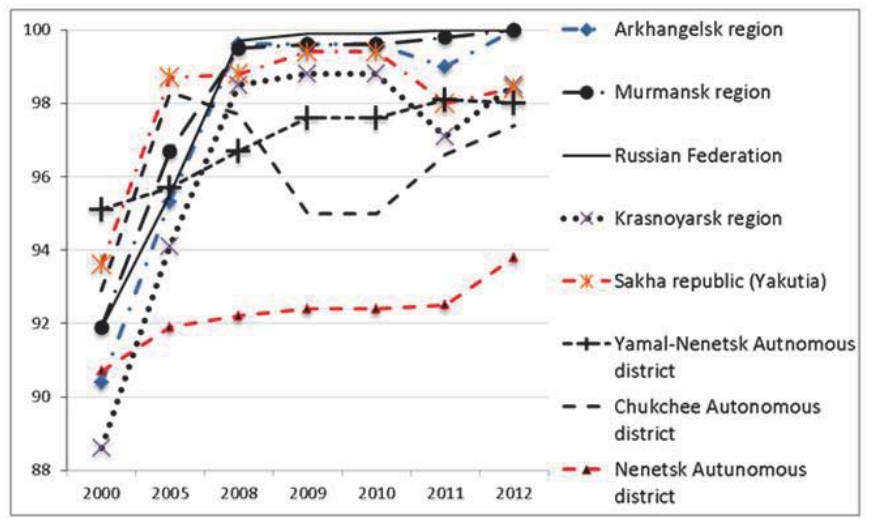

Figure 1. The dynamics of the PMI for the Russian circumpolar regions, 2000-2012.

The data source http://mod.vscc.ac.ru. The tables are composed by the Institute of social and economic regional development (city of Vologda) with the help of analytical information system of Russian regional modernization (IS "Modernization", Pat.No №2012661285, 2012). The methodological support of the RAS Philosophic Institute. The tables include detailed data, including the data obtained from MSC of the Chinese Academy of Sciences.

Figure 1 depicts common problems for the whole Russia, i.e. the modernization pace slows down as we move from the central part to the North and to the East. Here the natural resources without any valid mechanism for converting them into socio-economic advantages do not determine leadership of the region. For example we can mention a qualitative difference in realization of the primary modernization of the Yamal-Nenetsk and the Nenetsk autonomous regions.

Even more significant becomes lagging of the Russian northern regions with taking of the indicators of the secondary modernization into analysis.

The secondary modernization should result in forming of the high-tech society, information advances, development of services, network interaction, dissemination of IT, readiness for innovations, life-long learning etc.

During the 2010 Russia has entered the phase of transition to the secondary modernization, whereas Moscow achieved the SMI level of 104.5 points. Some of the regions however are pretty much behind this value. Up to 2012 the number of countries monitored by the MSC of the Chinese Academy of Sciences was already 135. The total number of countries that have reached the information modernization stage is about 40; over 90 countries were still on the stage of primary modernization and 4 countries were fully agricultural societies.. The SMI indices between the countries were in the range from 18 up to 108 points. In the information-developed countries the USA was the leader with SMI of 108 points. Russia turned out to be medium developed with its 74.4 points, ranked $28^{\text {th }}$. China is pre-developed (54 points, rank 51).

Russia was ranked $28^{\text {th }}$ with SMI of 74.4 in 2012 which was a bit ahead of Kuwait. Only four medium-developed countries (Greece, the Czech Republic, Itlaly and Portugal) separate Russia from the information-developed countries. In 2006-2012 the Russian IMI-index grew from 59 to 67 points. However because of competition with other countries this increase has lead only to a two steps higher rank (rank 35 from the rank 37). The modernization processes in Russia are inhibited by low-quality market and management institutes.

Out of 12 components of the Russian IMI index only the number of doctors per 1000 pers. was at the level of $100 \%$. All the other indicators has shown positive dynamics, whereas all the other countries were also developing. As a result the realization of the integrated modernization increased from 51.1\% in 2000 to only $67 \%$ in 2012.

The most adverse situation was in the knowledge innovation sphere (only 294 people out of $1 \mathrm{mln}$. population applied for a patent, which is $44.5 \%$ of the level of the developed countries; the share of R\&D expenditures in the GRP was only $1.1 \%$, which is $45.8 \%$ of the level of the developed countries; the ecological effectiveness: per capita GRP divided by per capita energy expenses (in USD) was only $1.9 \%$ which is $20.9 \%$ of the level of the developed countries) (see Table 2). 
Table 2: The components of the IMI index for the Russian Federation for the period 2000-2012

\begin{tabular}{|c|c|c|c|c|c|c|}
\hline \multirow{2}{*}{ Russian Federation } & \multicolumn{3}{|c|}{2000} & \multicolumn{3}{|c|}{2012} \\
\hline & Real & Standard & Index & Real & Standard & Index \\
\hline The per capita Gross Regional Product (GRP) in USD & 1660 & 27680 & 6 & 12740 & 43176 & 29,5 \\
\hline The share of the added value in services out of the total GDP, in \% & 54 & 68 & 79,4 & 56,2 & 74,9 & 75 \\
\hline The per capita Gross Regional Product (GRP) at purchasing power parity in USD & 8010 & 27770 & 28,8 & 22710 & 40612 & 55,9 \\
\hline The share of the population employed in services out of total employed, in \% & 59 & 70 & 84,3 & 62,5 & 74,2 & 84,2 \\
\hline The integrated economic index & & & 49,6 & & & 61,1 \\
\hline The share of urban population, in $\%$ & 73 & 79 & 92,4 & 74 & 80,3 & 92,2 \\
\hline The number of doctors per 1000 pers. & 4,2 & 3 & 100 & 4,91 & 2,9 & 100 \\
\hline The life expectancy in years & 65 & 78 & 83,3 & 70,24 & 80,7 & 87 \\
\hline $\begin{array}{l}\text { The ecological effectiveness: the per capita GRP divided by per capita energy consumption (in USD), } \\
\% \text {. }\end{array}$ & 0,4 & 4,9 & 8,2 & 1,9 & 9,1 & 20,9 \\
\hline The integrated social index & & & 71 & & & 75 \\
\hline $\begin{array}{l}\text { The share of university students out of the population aged } 18-22 \text { years old, \%; the number of Internet } \\
\text { users per } 100 \text { pers. }\end{array}$ & 41 & 62 & 66,1 & 76,14 & 77,9 & 97,7 \\
\hline The share of R\&D expenditures in the GRP (GDP), in \% & 1,1 & 2,6 & 42,3 & 1,1 & 2,4 & 45,8 \\
\hline The number of residents applied for a patent per $1 \mathrm{mln}$. of population & 138 & 926 & 14,9 & 294 & 660 & 44,5 \\
\hline The number of personal computers per 100 households & 6 & 85 & 7,1 & 86 & 120 & 71,7 \\
\hline The integrated knowledge index & & & 32,6 & & & 64,9 \\
\hline The integrated modernization index & & & 51,1 & & & 67 \\
\hline
\end{tabular}

The data source http://mod.vscc.ac.ru. The tables are composed by the Institute of social and economic regional development (city of Vologda) with the help of analytical information system of Russian regional modernization (IS "Modernization", Pat.No №2012661285, 2012). The methodological support of the RAS Philosophic Institute. The tables include detailed data, including the data obtained from the MSC of the Chinese Academy of Sciences.

Let's analyze the place of the Russian circumpolar regions in the international context (see Figure 2).

All the Russian arctic regions are lagging behind the average Russian secondary modernization pace. In 2012 the SMI index of the Arkhangelsk region was 65.1 points, the Chukchee autonomous region SMI was 64.3 which is over 10 points lower the average Russian level. The Krasnoyarsk region performed with SMI of 69.2, the Yakut republic demonstrated the SMI of 69.3 points, the Yamal-Nenetsk autonomous region showed the SMI of 69.8 points (5 points lower the Russian average). Only the Murmansk region s almost equal the Russian average development pace, thought a bit lower with 73.3\% SMI in 2012.

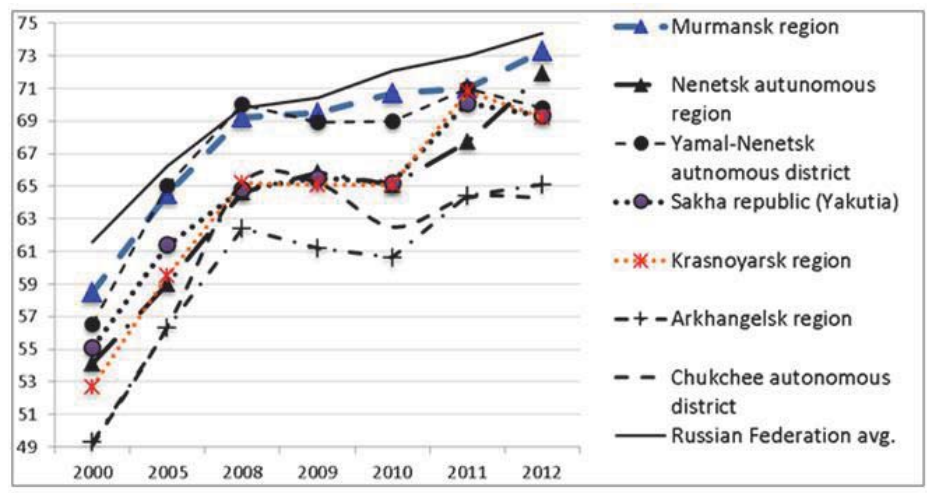

Figure 2. The dynamics of the SMI indices for the Russian circumpolar regions for the period 2000-2012

The data source http://mod.vscc.ac.ru. The tables are composed by the Institute of social and economic regional development (city of Vologda) with the help of analytical information system of Russian regional modernization (IS "Modernization", Pat.No №2012661285, 2012). The methodological support of the RAS Philosophic Institute. The tables include detailed data, including the data obtained from the MSC of the Chinese Academy of Sciences.

Both the quality of life index and related to it knowledge translation index in the analyzed regions and in Russia as a whole show good dynamics. That can by primarily explained with development of the Russian extractive industry. Some 
northern regions of Russia (Yamal-Nenetsk and Nenetsk autnomous districts) even exceed the average Russian level regarding the quality of economics index. The latter can also be explained with high level of per capita GRP because of extractive industry. But in Arkhangelsk and Krasnoyrsk regions this index is lower (50.2\% and $51.3 \%$ respectfully) (see Table 3).

Table 3: The dynamics of the SMI index and its' components during the period 2000-2012

\begin{tabular}{|l|c|c|c|c|c|}
\hline Regions & $\begin{array}{c}\text { Knowledge } \\
\text { innovation index }\end{array}$ & $\begin{array}{c}\text { Knowledge } \\
\text { translation index }\end{array}$ & Quality of life index & $\begin{array}{c}\text { Quality of } \\
\text { economics index }\end{array}$ & $\begin{array}{c}\text { Secondary } \\
\text { modernization index }\end{array}$ \\
\hline Russia & $55,7 / 55,7$ & $59 / 93,6$ & $82,3 / 94,9$ & $49,5 / 53,5$ & $61,6 / 74,4$ \\
\hline Murmansk region & $30,8 / 32$ & $65 / 103,7$ & $88,6 / 103,3$ & $49,5 / 54,2$ & $58,5 / 73,3$ \\
\hline Nenetsk autonomous region & $6,8 / 5,5$ & $60,6 / 95,4$ & $74,9 / 104,6$ & $74,1 / 82,2$ & $54,1 / 71,9$ \\
\hline Yamal-Nenetsk autnomous region & $3,5 / 4,2$ & $71,4 / 96,4$ & $85,9 / 95,1$ & $65,2 / 83,2$ & $56,5 / 69,8$ \\
\hline Sakha republic (Yakutia) & $28,6 / 26,2$ & $64,6 / 102,2$ & $78,6 / 90,7$ & $48,6 / 58,2$ & $55,1 / 69,3$ \\
\hline Krasnoyarsk region & $26,1 / 36,9$ & $62,3 / 95$ & $79,5 / 93,6$ & $42,7 / 51,3$ & $52,7 / 69,2$ \\
\hline Arkhangelsk region & $12,2 / 13,2$ & $59,9 / 99,1$ & $82,7 / 98,1$ & $42,3 / 50,2$ & $49,3 / 65,1$ \\
\hline Chukchee autonomous district & $11,2 / 3,1$ & $60,2 / 97,2$ & $76,3 / 83,1$ & $48,5 / 73,9$ & $49,1 / 64,3$ \\
\hline
\end{tabular}

The data source http://mod.vscc.ac.ru. The tables are composed by the Institute of social and economic regional development (city of Vologda,Russia) with the help of analytical information system of Russian regional modernization (IS "Modernization", Pat.No №2012661285, 2012). The methodological support of the RAS Philosophic Institute. The tables include detailed data, including the data obtained from the MSC of the Chinese Academy of Sciences.

The most successful (Yamal-Nenetsk autnomous district and Murmansk region) and the most lagging (Arkhangelsk region) regions of the Russian Arctic in respect to modernization are both reflecting all serious problems of economics and social sphere.

The Yamal-Nenetsk autnomous district (YNAD) is situated in the Arctic zone of the West-Siberian plain and on the East side of the Polar and sub-Polar Ural mountains. The Yamal-Nenetsk autnomous district covers distance of $1150 \mathrm{~km}$ from the North to the South and $1130 \mathrm{~km}$ from the East to the West. The whole territory of the YNAD is the so called Far North (over a half of the territory lies within the Polar circle) and it is 769.3 thd. sq.km. On the northwest it borders with the Nenetsk autonomous region, on the West it borders with the Komi republic. To the South the YNAD borders with KhantyMansi (lugra) autonomous district and on the East with the Krasnoyarsk region. The climate of YNAD can be characterized with long and severe winter (on average winter lasts for 182 days), frequent waves of cold, cyclones combined with storms and blizzards.

According to the statistics on 01.01 .2014 the territory is populated by 539.7 thousand people, the average monthly wage is 58040 RUR (rank 2 in Russia). Almost $84 \%$ of the population of the YNAD live in cities. But only the capital of the YNAD (Salekhard) can be called a medium-size city with population of about 50 thousand people.

The main production type of the region is extraction of hydrocarbons - gas, crude oil and gas condensate. The extraction of natural resources constitutes over $88 \%$ of the industrial production of the region. The volume of the yearly extracted natural gas within the region is responsible for over $80 \%$ of the Russian gas production and it is the fifth part of the world gas production. The volume of crude oil and gas condensate production of the YNAD is about $8 \%$ of the Russian production. The systematic problems of the territory are insufficient works of exploration and prospecting, declining volumes of oil extraction, low effectiveness of the so called associated gas usage in oil an gas condensate extraction. Also a problem of "low pressure" gas usage exists.

The level of wages in the region is one of the highest in Russia (monthly wage of 58040 RUR in the region against the Russian monthly average wage of 25928 RUR). High income and low population of the region determine the style and quality of life. The primary modernization in the YNAD is almost accomplished. Only the share of the added value in the sphere of services divided by GDP was $36.1 \%$ in 2012 , which is $80 \%$ of the standard value. As viewed by the quality of life (with an exception of high infant mortality index $-52.2 \%$ of the standard value) and knowledge translation the YNAD goes ahead of all its neighboring regions (see Table 3), but the knowledge innovation index is the lowest in the analyzed regions (4.2\%). In the YNAD there are only 0.85 researchers and engineers per 10000 people $(2.2 \%$ of the standard value), but the patent activity is notably higher than in the Nenetsk autonomous region $(11.2 \%$ of the standard value). The economics quality index is not very high because of lagging of the sphere of services (83.2\%). The IMI index that depends on the average of the 20 most developed countries is the highest of all the Russian arctic regions. However after 2008 it declines and in 2012 it was 67.8\%. Only three components out of 12 constituting the index have reached 
$100 \%$ (GRP, the share of urban population and the number of doctors), while the R\&D expenditures are only $0.01 \%$ of GRP, which is only $0.4 \%$ of the standard value. The ecological effectiveness is only $20.9 \%$ of the standard value (Figure 3).

The Murmansk region occupies about 144.9 thousand sq.km. and it is populated by 771.1 thousand people as of 01.01.2014. This is the most western Russian arctic region, it borders with Finland. The territory is bordered by the Barents sea and the White sea and includes the Kola peninsula. The geographic location has determined the regional specialization, that is the Russian border outpost. Transport, extraction of natural resources sea fishing and defense industry are traditional leading branches. The economic structure is more diversified than in the other northern regions. The major industries are: $18.6 \%$ extraction of natural resources, 15\% manufacturing, $9.6 \%$ trade, $9.4 \%$ state governance, $7.6 \%$ fishing and fish farming. However according to the statistics of 2014 the share of the obsolete fixed assets in the region is rather high. The unemployment rate and dependence of the region on imports are rather high either. The industrial investments in 2014 decreased by $12 \%$ to the previous year. The crisis of 2008 have influenced negatively the modernization of the region through the years 2008-2010. The regional economic growth resumed only in 2011.

Judging by the level of realization of primary and secondary modernization the region is one of the most steadily developing. The pace of the integrated modernization in the region yields only the YNAD, but the balance of the IMI in the region is higher (balance is calculated as variance of the sub-indices). As of 2012 the primary modernization in the region is fulfilled at $100 \%$, the secondary modernization is completed only by $73.3 \%$. The knowledge innovation index lags behind the standard value (32\%) because of relatively low patent activity (103.8 people per $1 \mathrm{mln}$. population, which is $15.7 \%$ of the standard value). Also the rate of R\&D expenditures is $0.85 \%$ of GRP, which is $35.4 \%$ of the standard value, while the number of researchers and engineers is 17.5 per 10000 pers. which is $44.9 \%$ of the standard value. These indicators are lagging behind the Russian average ones (see Table 2). The latter is however offset by the higher personal income of the population (monthly wage of 32912 RUR in 2014), that is explained with the north bonuses. The integrated economic index of the region is not high (see Table 3 ) because of relatively low per capita GRP value (26.6\% of the standard) and low ecological effectiveness (20.9\% of the standard).

Thus, despite of the peripheral status of the region almost all the indicators of the Murmansk region show the average Russian dynamics (see Figures 1-3, Table 3).

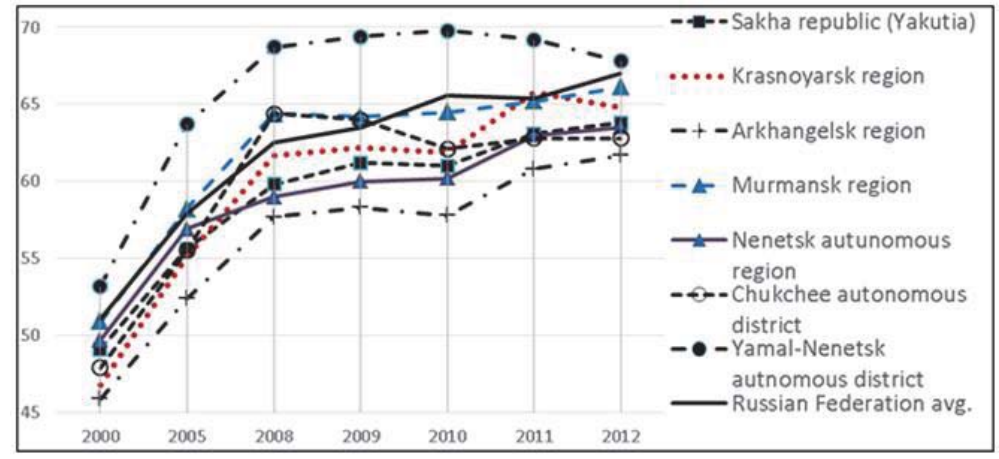

Figure 3. The integrated modernization dynamics in the Russian arctic regions for the period 2000-2012

The Arkhangelsk region has realized the primary modernization up to 2008 almost for $100 \%$ (see Figure 1). The fast growth of the beginning of the 2000s was changed in 2008 by a decline of several indicators (see Fig.1-3). As a result up to 2012 the per capita GRP was 12843 USD (28.9\% of the standard). Whereas the sphere of services in the region develops quite fast (the share of employed in services was $63.5 \%$ with standard value of $74.2 \%$ ). The population of the region is $1.15 \mathrm{mln}$. people, the total territory is 413.1 thousand sq. $\mathrm{km}$. The average personal income is about the Russian average (24475 RUR per month, 2014). The main development curb is low value of the knowledge innovation index. The share of R\&D expenditures was $0.24 \%$ of GRP, the number of researchers and engineers was 7.1 people per 10000 pers. and 75.4 people out of a mln. applied for a patent. The urbanization level is high $(76.6 \%$ of the population are living in the cities), the knowledge translation rate has reached $99.1 \%$ of the standard value. The quality of life index is about $98.1 \%$ of the standard, which haven't led to a substantial rise of the quality of economics index. The share of employed in agriculture and production have reached $36.4 \%$ with the standard of $26 \%$. The share of the added value in agriculture 
and production in GRP was only $48.1 \%$ of the standard. The integrated modernization of the region is also notably behind the Russian average level (see Fig.3).

The population of the Nenetsk autonomous region (NAR) is 43 thousand people living on the territory of 176.8 thousand sq.km. The economics of the NAR consists primarily of extractive industry (74\% of the GRP), which stipulates a relatively high average regional wage. The latter gives the higher quality of life index (104.6\%) and knowledge translation index (95.4\%). Herewith the knowledge economics in the NAR can be called non-existing. As of 2012 the share of R\&D expenditures was $0.03 \%$ of the GRP, the number of researchers and engineers was 6 people per 10000 pers. and nobody applied for a patent. That makes the index of knowledge innovation equal to $5.5 \%$ in 2012. These figures are of interest if one takes into consideration that the region has almost caught up the leading countries in respect to the share of students (101.5\%), to the share of high-school students (95\%), the number of TV sets (101.5\%) and the number of PC ( $73.3 \%$ of the standard).

The main indicators determining the progress in the modern economics based on knowledge of the Murmansk region haven't reached even $50 \%$ of the level of the developed countries. The other regions are still remaining in the paradigm of the resource-based economics, while the high level of primary modernization calculated with the MSC (Chinese Academy of Sciences) methodology is determined only by a high level of per capita GRP (YNAD, NAR and the Chukchee autonomous district).

\section{The Results of the Analysis}

a. All the Russian arctic regions are lagging behind the average Russian pace of the secondary modernization. The level of the secondary modernization of the Arkhangelsk region (65.1), and the Chukchee autonomous district (64.3) is 10 points below the Russian average. The Krasnoyarsk region (69.2), Yakutia (69.3) and the Yamal-Nenetsk autonomous district (69.8) are below about 5 points. The Murmansk region is about the Russian average level.

b. The quality of economics indicator of the Yamal-Nenetsk autonomous district and the Nenetsk autonomous distict are above the average Russian level. It is explained with high GRP per capita level due to extractive industries. In the Arkhangelsk region and the Kranoyarsk region this indicator is $50.2 \%$ and $51.3 \%$ of the Russian average level respectively.

c. The most successful regions in the modernization process are the Yamal-Nenetsk autonomous district and the Murmansk region. The most lagging region in terms of modernization is the Arkhangelsk region.

d. The main indicators that determine the progress of the modern knowledge-based economics in the Murmansk region are still below the $50 \%$ of the level of the developed countries.

e. In the economics of the Nenetsk autonomous region about $74 \%$ of the GRP is contributed by the extractive industries. The wage level is relatively high, which means higher both the quality of life index (104.6\%) and the knowledge translation index (95.4\%). But the knowledge-based economy in the region is not developing.

f. The integrated modernization in the Arkhangelsk region is substantially behind the average Russian level. The main development constraint is low innovation index.

\section{Acknowledgement}

This paper is based on research carried out with the financial support of the grant of the Russian Science Foundation (Project No. 14-38-00009).Peter the Great St. Petersburg Polytechnic University

\section{References}

Beck, U. (1992). Risk Society: Toward a New Modernity. London: Sage.

Beck, U., Giddens, A., and Lash, S.( 1994). Reflexive Modernization: Politics, Tradition and Aesthetics in the Modern Social Order. Stanford, California: Stanford University Press.

The development strategy of the Arctic zone of the Russian Federation and the national security for the period until 2020, approved by the President of the Russian Federation, February 8, 2013.

Didenko N.I., Skripnyuk D.F. (2014). The methodological principles of analysis of the world market of goods with the use of a system of interconnected econometric equations // MID (Modernization. Innovation. Development),19, 50-62.

He Chuanqi. (2012). Modernization Science. The Principles and Methods of National Advancement. Springer.

Huber, J.(1985). Die Regenbogengesellschaft; Okologieand Sozialpolitik. Frankfurt am Main; Fischer.

Lapin N.I. ( 2015). Recent theoretical and methodological aspects of research of Russian modernization. // Sociological researches, 1 
(369), 5-21.

Presidential Decree of May 2, 2014, № 296 "On the land territory of the Arctic zone of the Russian Federation", Russian Regions. Socioeconomic indicators. / Rosstat. Moscow.

Regions of Russia. Socio-economic indicators.( 2014): / Rosstat. Moscow.

Romashkina G. ( 2015). The processes of modernization in the regions of the Urals Federal District. // Sociological researches, 1 (369), 19-26.

Tatarkin A.I.(2014). The Russian Arctic: a modern paradigm of development. St. Petersburg: Nestor-story.

State program "Socio-economic development of the Arctic zone of the Russian Federation until 2020", approved by RF Government Decree 21 April 2014.

A survey report on the modernization of the world and China (2001-2010).(2011) Edited Chuantsi Ho. Russian transl. ed. N.I. Lapin. Moscow.

Tiryakian, E. (1991). Modernization; Exhumetur in Pace (Rethinking Macrosociology in the 1990s'). International Sociology 6 (2) (1991).

P. $165-180$.

Vasiliev Y.S., Didenko N.I. (2011). Innovation and global economy // Geopolitics and Security.1 (13), 65-74.

Zapf, W. (1991). ed. Die Modernisierung Moderner Gesellschaften. Frankfurt; Campus Verlag 